\title{
ISLAM DI SICILIA: Asal-usul, Kemajuan dan Kehancuran
}

\author{
M. Fajrul Munawir \\ Universitas Gadjah Mada. Fakultas Filsafat. Yogyakarta. Jalan Bulaksumur Jogjakarta. Tlp. (0274) 54943. \\ e_mail: Fajrul@gmail.com
}

Abstract

Islam authority in Sicilia was being parts of history of Islamic civilization in Europe. The aim of this article is tried to explain background, progression and decline of Islam in Sicilia. Glory of Islam in Sicilia had started in Bani Aghlab period. Bani Aghlab period had already been shaping the important civilization of spreading Islam in Europe 184 H/800 M. Sicilia become center of science and Islamic culture in Europe. Great Land is epithet of prosperity in Sicilia. Decline of Sicilia had appeared when reformation authority from Aghlabiyah to Fatimiyah. Christian Romawi succeeded dominate Sicilia in 871 M until 1090 M. Finally, Sicilia had been formed golden history and spreading Islamic civilization in Europe.

Key words: Islam, sicilia, europe

\section{Pendahuluan}

Ketika Baghdad diperintah oleh Harun al Rasyid, di bagian Afrika Utara terdapat bahaya besar yang mengancam kewibawaannya. Pertama dari Dinasti Idrisi yang beraliran Syi'ah. Kedua dari kaum Khawarij. Sementara 
stabilitas keamanan di Tunisia tidak menentu akibat kematian Gubernur al Qadir Yazid ibn Hatim al Mahlabiy (Ali, 1996: 583).

Adanya kedua ancaman tersebut telah mendorong al Rasyid menempatkan bala tentaranya di Ifriqiyah di bawah pimpinan Ibrahim Ibnu al Aghlab. Setelah berhasil menciptakan keamanan di wilayah ini terutama dengan menumpas kaum Khawarij, Ibrahim mengusulkan kepada al Rasyid agar wilayah gubernuran Ifriqiyah di hadiahkan kepadanya dua keturunannya secara permanen. Jika hal ini terjadi ia tidak hanya akan memerintah dan menjamin ketentraman di propinsi tersebut, tetapi juga akan mengirim upeti tahunan ke Baghdad empat puluh ribu dinar. Harun al Rasyid menerima tawaran tersebut dari Ibrahim. Dengan demikian Kriqiyah menjadi propinsi yang mempunyai hak-hak otonomi penuh, meskipun masih mengakui kekhalifahan Baghdad (Bosworth, 1993: 46).

Selama lebih dari satu abad, Ifriqiyah diperintah oleh keturunan al Aghlab. Kemakmuran yang dicapai oleh rakyat dan pemerintah Ifriqiyah, ditambah dengan adanya perbedaan antara orang-orang Arab dan orangorang Barbar telah mendorong mereka untuk mencari tanah baru. Faktor ini turut membangkitkan semangat bani Aghlab untuk menduduki Sicilia dan sebagian Italia selatan selama abad sembilan masehi.

Berangkat dari pemaparan di atas, penulis mencoba menguraikan secara singkat sejarah Islam di Sicilia mulai dari asal-usul, kemajuan dan kehancurannya.

\section{Kekuasaan Islam di Sicilia}

Pada masa Daulah Bani Umayah (661-750 M) wilayah kekuasaan dan daerah jajahan Islam telah merebak ke seluruh Afrika Utara, Spanyol dan Sicilia di Eropa. Bahkan hal itu semenjak Muawiyah Ibnu Sufan menjabat gubernur di Syiria, dilanjutkan ketika ia menjabat sebagai khalifah (Ibrahim, 1977: 144).

Akan tetapi kekuasaan Islam atas Sicilia mulai eksis sejak pemerintahan Bani Aghlab atas nama Daulah Abbasiyah. Otonomi yang besar atas Kriqiyah (Tunisia Modern) yang diberikan Kalifah Harun al Rasyid (pemerintah pusat 
Daulah Abbasiyah) pada tahun 184 H/800 M. memberikan kekuasaan Aghlabiyah dalam menentukan policy pemerintahannya, termasuk perluasan daerah Sicilia. Proyek besar merebut Sicilia ini dimulai pada tahun 212 H/827 M ketika Aghlabiyah diperintah oleh amir yang kedua yaitu Ziyadatullah Ibnu Ibrahim. Penaklukan dan penyerangan Aghlabiyah atas Sicilia dilatarbelakangi oleh adanya ketegangan intern penguasa Romawi. Pada tahun $211 \mathrm{H}$ kaisar Romawi memerintahkan Gubernur Sicilia yang bernama Konstantin untuk menangkap Euphemius (Ibrahim, 1977: 145).

Perintah penangkapan tersebut disambut pasukan Euphemius sehingga pertempuran antara pasukan Euphemius dan pasukan Konstantin tidak dapat dielakkan. Keadaan yang terdesaklah yang menyebabkaii Euphemius akhirnya memaksanya untuk meminta bantuan kepada Ziyadatullah dengan menawarkan kekuasaan atas Sicilia. Kesempatan ini tidak disia-siakan olehnya dan segera dikirim bala bantuan pasukan tempur yang dipimpin oleh Asad Ibnu al Furat (Amin, 1996: 308). Pada bulan Rabiul Awal tahun $212 \mathrm{H}$ pasukan yang dipimpin oleh Asad Ibnu al Fuarat tersebut berangkat dengan tentara yang memiliki semangat jihad yang tinggi yang memang saat itu mayoritas penduduk Ifriqiyah adalah orang-orang taat pada ajaran Islam. Sehingga kepergian mereka tidak sekedar pembelaan atas suatu madzhab, tetapi lebih dari itu keberangkatan mereka adalah sebagai pejuang pembela kebenaran yang diyakini sebagai jihad fisabilillah.

Pasukan tersebut tiba di kepulauan Sicilia dan langsung menaklukkan Mazzora dilanjutkan mengepung Sarkosah. Akan tetapi sebelum tercapai para pejuang banyak yang berguguran, termasuk panglima perangnya, yaitu Asad Ibnu al Furat. Sehingga kedudukannya digantikan oleh Muhammad Ibnu al Jawari sehingga menguasai wilayah tersebut. Kemudian setelah al Jawari meninggal dunia kedudukannya digantikan oleh Zuhair Ibnu al Ghaust. Akhirnya serangan bergelombang pasukan Aghlabiyah menyebabkan jatuhnya satu demi satu kota atau benteng di Sicilia: Palermo, Kastroglovami, Girgento, Catania, Messing dan lain-lainnya ke tangan dinasti ini. Dengan jatuhnya Syracuse pada tahun $264 \mathrm{H} / 878 \mathrm{M}$ penaklukan seluruh pulau Sicilia oleh dinansti Aghlabiyah menjadi sempurna dengan Palermo sebagai ibukotanya 
(Syalaby, 1996: 43). Dari Sicilia sebagai markas dan basis, serangan dinasti ini ditujukan ke pulau-pulau lainnya dan pantai-pantai di Eropa. Pasukan dinasti ini berhasil menaklukkan kota-kota pantai Itali: Brindisi $(836 \mathrm{M} . / 225 \mathrm{H})$, Bari (841 M/226 H), Benevinto (842 M/227 H). Pada masa pemerintahan Abu al Abbas Muhammad, seorang letnan dari Sicilia yang bernama Fadil ibnu Ja'far Hamdani mendarat di Messina tahun $228 \mathrm{H}$ beserta kota kecil lainnya. Kemudian pada dekade selanjutnya penaklukkan berlanjut terus ke Catania tahun 236 H Kaltavuturo tahun 239-340 H, Noto, Abba, Sates, Castelnuovo tahun $250 \mathrm{H}$, Malta $255 \mathrm{H}$.

Karena serangan yang berkepanjangan terhadap bandar-bandar Itali: termasuk kota Roma, maka Paus Yohanes Vffl (872-882 M) tidak tahan dan terpaksa minta damai dengan meminta pasukan Aghlabiyah untuk meninggalkan wilayah sekitar Roma dan bersedia membayar upeti sebesar dua puluh lima ribu perak pertahun (Nasution, 1992: 21). Penaklukan Syracus tahun 264 H/878 M merupakan kesempurnaan penguasaan Dinasti Aghlabiyah atas Sicilia. Selanjutnya, pulau itu di bawah kekuasaan gubernurgubernur Fatimiyah sampai panaklukan oleh Norma pada abad kesebelas.

Daulah Fatimiyah mulai menguasai Sicilia sejak masa Ubaidillah al Mahdi berhasil mengalahkan Aghalabiyah. Hal tersebut bermula ketika khalifah pertama Ubaidillah al Mahdi datang dari Suriah ke Afrika Utara, di saat posisi Dinasti Aghlabiyah di Ifriqiyah turun pada akhir abad ke sembilan. Propaganda yang dilancarkan oleh Abdullah al Syi'i atas isyarat Ubaidillah al-Mahdi telah menanamkan pengaruh yang kuat di kalangan orang-orang Barbar suku Ketama. Kesenjangan antara para penguasa; Aghlabiyah di satu pihak dan orang-orang Barbar di pihak lain telah menambah kuatnya pengaruh itu yang akhirnya menumbuhkan kekuatan militer (Ibrahim, 1977: 88).

Pada tahun 1909 kekuatan tersebut pada akhirnya benar-benar mampu menggulingkan penguasa Aghlabiyah terakhir, yaitu Ziyadatullah III. Semenjak itu Ifriqiyah dikuasai oleh orang-orang Syi'ah yang selanjutnya membentuk Dinasti Fatimiyah. Ketika masa Khalifah Muiz li Dinillah hukum diterapkan dengar bijaksana warga negara Sicilia diperlakukan dengan sebaik-baiknya situasi di daerah itu dipelajari dengan sungguh-sungguh dan strategi disusun 
sedemikian rupa untuk mempertahankan Sicilia dalam kekuasaannya. Di sisi lain, pe-nguasa Romawi tiada henti-hentinya berusaha untuk merebut kembali dari genggaman umat Islam. Walaupun demikian, warga Sicilia tetap lebih senang diperintah oleh orang Islam. Pada tahun 1025 M. Romawi berusaha mengambil Sicilia, namun warga Sicilia tetap menyatakan setia kepada pemerintah Islam (Hasan, 1977: 113).

\section{Kemajuan Islam di Sicilia}

Sicilia berkembang dengan pesat ketika pulau itu dikendalikan oleh kekuasaan Islam. Penaklukan dan pendudukan Bani Aghlab telah membentuk suatu peradaban yang penting bagi penyebaran Islam ke Eropa. Kristen Bahkan renaisans di Italia terjadi karena transmisi ilmu melalui pulau ini.

Sicilia merupakan pusat ilmu pengetahuan dan kebudayaan Islam. Sehingga islamisasi sains dan kultur Islam mewarnai Sicilia dan sekitarnya (Gruneboun, 1969: 234). Banyak masjid dan perguruan tinggi didirikan, seperti di Paleno yang setiap saat dipadati jamaah, juga seperti universitas yang telah didirikan di kota tersebut yang mana kebesarannya mampu menandingi Universitas Cordova dan Baghdad (Bosworth, 1993: 329).

Kemakmuran yang dialami oleh Sicilia telah memperoleh julukan great land bersama Spanyol. Banyak deretan nama-nama yang masyhur dalam berbagai bidang disiplin keilmuan, seperti sang panglima penakluk Sicilia Asad Ibnu al Furat yang ahli dalam bidang fiqih, bahasa dan perang, Jauhar al Siqli yang ahli perang, Muhammad Ibnu Khurasan yang ahli bahasa dan Muhammad ibnu al Hasan Ibnu Ali yang ahli dalam fiqih serta masih banyak sederetan nama-nama lainnya, sehingga kultur Islam benar-benar sangat menonjol dan mewarnai kehidupan masyarakat Sicilia yang bermadzhab Maliki (Amin, 1996. 121).

Toleransi dan kehidupan beragama di Sicilia sangat kuat. Keadaan ini berlangsung hingga jatuhnya Islam ke kekuasan Kristen. Kebudayaan Islam masih memberikan pengaruh yang kuat dalam kehidupan Sicilia selanjutnya. Dalam bidang ekonomi, Sicilia tergolong daerah produsen yang maju. Sicilia mengadakan kontak dagang dengan negara tetangga dengan mengekspor 
jagung dan daging onta ke Afrika Utara dan mengimpor bahan bakar dari Mesir (Amin, 1996: 164-165).

\section{Kemunduran dan Kehancuran Islam di Sicilia}

Tanda-tanda datangnya kemunduran yang pada akhirnya membawa kehancuran kekuasaan Islam di Sicilia ini sebenarnya sudah ada semenjak pergantian kekuasan dari Aghlabiyah ke Fatimiyah. Hal tersebut ditandai dengan ketidaksukaan orang-orang Sicilia terhadap gubernur yang dikirim oleh penguasa Fatimiyah ke Sicilia, yang sedemikian itu tumbuh oleh adanya perebutan pengaruh yang dilancarkan oleh Daulah Abbasiyah dan Fatimiyah di samping adanya perbedaan aliran antara keduanya (Hamka, 1976: 171).

Di sisi lain, ada semacam usaha yang tidak henti-hentinya yang datang dari penguasa Kristen Romawi untuk mengembalikan Sicilia ke pangkuannya. Pada akhirnya hal itu menjadi kenyataan, ketika terjadi perebutan kembali kota Bari oleh mereka pada tahun 871 di mana merupakan permulaaan berakhirnya ancaman muslim untuk Italia dan Eropa tengah. Selanjutnya pada tahun 880. Kaisar Basilius I dari Bizantium memerdekakan Taranto, sebuah kota pertahanan lainnya yang penting dari tangan muslim: beberapa tahun kemudian menyusul Calabria, pada saat selanjutnya datang orangorang Norma yang dimotori oleh Count Roger putra Tandered de Hautaville menguasai kota Messina pada tahun 1060, kota Palermo tahun 1071, Syracuse tahun 1084 dan akhirnya Malta pada tahun 1090.

Dengan demikian berakhirlah sejarah ekspansi yang dimulai dua setengah abad yang lalu di Arabia. Kini menara-menara Saracenia itu tinggal sebuah kenangan dan saksi bisu semata serta menjadi hiasan keindahan pantai selatan Napeles.

\section{Simpulan}

Sejarah telah mencatat bahwa Islam telah berkuasa di belahan bumi Eropa dan Italia termasuk Sicilia. Ia telah hadir mewarnai dunia Sicilia; membentuk suatu pusat yang penting bagi penyebaran peradaban Islam ke Eropa. Lebih dari itu renaissance di Italia terjadi karena transmisi ilmu pengetahuan melalui 
pulau ini. Kini supremasi itu tinggal kenangan, Islam tertinggal dengan Eropa. Untuk itu dunia Islam mesti bangkit untuk meraih kembali zaman keemasan yang pernah dicapai.

\section{Daftar Pustaka}

Ali. 1996. A Studi of Islamic History. Diterjemahkan oleh Ghufran A. Mas'adi. Jakarta: Raja Grafindo Persada.

Amin, Ahmad. 1996. Dhuhr al Islam. Cairo: Maktabah al Nahdliyah al Mishriyah.

Bosworth. 1993. The Islamic Dynasties. Diterjemahkan oleh Ilyas Hasan. Bandung: Mizan.

Gruneboum. 1969. Islam, Essays in The Nature and Orouth of Cultural Tradition. London: Rautledge and Kegan.

Hamka. 1976. Sejarah Umat Islam II. Jakarta: Bulan Bintang.

Ibrahim, Hasan. 1977. Al Daulat al Fatimiyah. Mesir: Multazamah al Nasyr wa al Tab.

Nasution, Harun. 1992. Ensiklopedi Islam Indonesia. Jakarta: Djambata.

Syalabi, Ahmad. 1996. Mausu'ah al-Tarikh al-IsLam wa al Hadlarat al Islamiyah. Cairo: Maktabah al Mishriyah. 